\title{
Advances in Treatment of Pediatric Brain Tumors
}

\author{
Patricia L. Robertson, M.D.
}

\begin{abstract}
Summary: The long-term survival of children with brain tumor has improved considerably in the last three decades, owing to advances in neuroimaging, neurosurgical, and radiation therapy modalities, coupled with the application of conventional chemotherapy. MRI, MR spectroscopy and diffusion-weighted MRI have contributed to more accurate diagnosis, prognostication and better treatment planning. Neurosurgical treatment has been advanced by the use of functional MRI, and intraoperative image-guided stereotactic techniques and electrophysiologic monitoring. The use of 3-D conformal and intensitymodulated radiation therapy, stereotactic radiosurgery, and radiosensitizing agents has made radiation therapy safer and more effective. Conventional chemotherapy, administered either alone or combined with radiation therapy has improved survival and quality of life of children with brain tumors. These improved outcomes have also occurred, due, in part, to their
\end{abstract}

treatment on collaborative national and international studies. Recent promising diagnostic and therapeutic strategies have resulted from advances in understanding molecular brain tumor biology. Important new approaches include the refinement of drug-delivery strategies, the evaluation of biologic markers to stratify patients for optimal treatment and to exploit these molecular differences using "targeted" therapeutic strategies. These approaches include blocking tumor cell drug resistance mechanisms, immunotherapy, inhibition of molecular signal transduction pathways important in tumorigenesis, anti-angiogenic therapy, and gene therapy. The thrust of such approaches for children with brain tumors is especially directed at reducing the toxicity of therapy and improving quality-of-life, as well as increasing disease-free survival. Key Words: Pediatric brain tumor, neurosurgery, radiation therapy, chemotherapy, immunotherapy, small molecule.

\section{INTRODUCTION}

Central nervous system malignancies are the most common solid tumors in childhood, and are the leading cause of cancer-related death in this age group. Over the last two to three decades, advances in neuroradiologic and other diagnostic/prognostic modalities, neurosurgical and radiation therapy (RT) techniques, and the application of chemotherapy, are responsible for the considerable improvement in the long term survival of children with brain tumors. Yet, a significant proportion still die of their disease. Moreover, in long term survivors, the potential adverse effects of therapy may negatively influence neurologic function and quality of life. Recent advances in molecular and cellular brain tumor biology have resulted in better understanding of tumor classification and biologic staging, and of specific molecular mechanisms of tumorigenesis or resistance to chemotherapy. This knowledge has created new strategies of targeted

Corresponding Author Patricia L. Robertson, M.D. University of Michigan Health System Department of Pediatrics and Neurology, Division of Pediatric Neurology, 1500 E. Medical Center Dr., L3215 Women's Hospital, Ann Arbor, MI 48109-0203, Phone - 734-9364179, Fax - 734-763-7551. E-mail: prob@med.umich.edu therapies that exploit differences between neoplastic and normal cells, permitting more effective therapy to be aimed directly at the tumor, while sparing normal tissue, and leading to fewer long term adverse sequelae of treatment. In some targeted therapies, the therapeutic agents are ligands for specific tumor cell surface receptors or antigens not present on normal cells that kill tumor cells by virtue of linkage to toxins or radioisotopes. Others work by blocking specific mechanisms of tumorigenesis, such as tumor angiogenesis or oncogene-altered cellular signal transduction pathways. Other new strategies include forms of immunotherapy and gene therapy. Ongoing and future clinical trials with these novel therapies should continue to improve survival and quality of life of children with brain tumors.

This review will address advances in conventional diagnostic and prognostic modalities (neuroimaging, tumor histopathology and biologic markers) and therapeutic modalities (surgery, radiation therapy, chemotherapy) that have contributed to the improved outcome of children with brain tumors, and present an overview of new investigational therapeutic approaches. Specific current and possible future management strategies for several common pediatric brain 
tumors, including medulloblastoma/PNET, and highgrade and low-grade gliomas, are reviewed.

\section{DIAGNOSTIC/PROGNOSTIC MODALITIES}

An accurate diagnosis is of obvious importance in selecting optimal therapy for a child with a brain tumor. The ability to predict the biologic behavior of a tumor is tightly linked to accurately stratifying patients for treatment, to separate those who require more intensive therapy from those in whom less aggressive therapy may be justified without a reduction in survival. Thus, advances in diagnostic and prognostic modalities are integral to progress in the treatment and outcomes of children with brain tumors

MRI/MRS/diffusion MRI. Magnetic Resonance Imaging (MRI) has been paramount in accomplishing the non-invasive diagnosis of brain tumors. Some pediatric brain tumors are so characteristic on MRI, that if they have a clinically typical presentation, no tissue diagnosis is required before treatment, including some optic pathway/hypothalamic gliomas, low-grade tectal midbrain gliomas, and malignant pontine gliomas. ${ }^{1-3}$ MRI aids the surgical approach for the majority of tumors which require surgery to establish the histologic diagnosis and reduce tumor burden. MRI can also be coupled to imageguided stereotactic techniques, either for stereotactic biopsy of deep-seated lesions deemed high-risk for resection, or to aid in the approach for an open biopsy and attempt at a more extensive resection. MRI is also of enormous value in tumor-staging. A post-operative brain MRI performed within the first 24-48 hours gives a more accurate assessment of residual tumor volume than was provided by CT. As well, MRIs are more sensitive and easier to perform than myelograms for detecting leptomeningeal spread within the neuroaxis.

Magnetic resonance spectroscopy (MRS). MRS permits the measurement of multiple chemical metabolites in normal and abnormal brain parenchyma; abnormal patterns have been identified in brain tumors. ${ }^{4}$ The level of choline and the ratio of choline-to-creatinine, or choline-to-N-acetyl aspartate (NAA) in a lesion correlate with higher cellular proliferation rate, and reflect the presence of a more malignant and rapidly growing tumor. NAA is considered a neuronal membrane marker, which decreases with replacement of neurons by tumor (or other non-neuronal tissue, including necrosis). Decreased choline may represent tissue destruction, reflecting either spontaneous or therapy-related tumor necrosis. In the management of brain tumors, MRS is most valuable in the evaluation of whether MRI changes represent treatment-related effects or recurrent disease; it may also prove useful in the assessment of tumor response to therapy. ${ }^{5}$
Diffusion-weighted MRI. The use of diffusionweighted MRI is currently being explored to identify parameters of tissue change at a cellular level that might help predict tumor response to therapy. ${ }^{6}$ Diffusionweighted MRI measures the molecular mobility of extracellular water; alterations in water mobility appear to reflect treatment-induced changes in tissue structure. Current understanding is that water diffusion increases acutely in tumors responsive to therapy. This precedes changes in tumor volume. This early indicator of treatment response and outcome before completion of therapy may permit tailoring of treatment in a more timely fashion. ${ }^{7}$

\section{Tumor classification/prognostication}

Histopathology. Assessment of the histologic characteristics of a tumor by light and sometimes electron microscopy, is necessary for their diagnosis/classification, and aids in grading the degree of anaplasia for those tumors in which grade is useful for prognosis. The number of tumor mitoses in a microscopic field, the traditional measure of cellular proliferation, also helps assign tumor grade. However, a newer approach to evaluating cellular proliferation employs immunostaining of Ki-67, a nuclear antigen expressed in certain phases of the cell cycle, using the equivalent monoclonal antibody MIB- $1 .{ }^{8}$ The MIB-1 proliferation index correlates with the biologic behavior and prognosis of low-grade and malignant gliomas in children, ${ }^{9,10}$ and in medulloblastomas, where "hot spots" of high proliferation rate were predictive of poor outcome. ${ }^{11}$

Genetic tumor markers. Recently, the detection of molecular genetic traits of pediatric brain tumors is providing new information to classify tumors and predict prognosis. This should translate to more accurate riskstratification than traditional tumor grading and staging, and ultimately, to better treatment outcomes. Some of the genetic alterations of pediatric brain tumors differ from those of adults. For example, p53 mutations were found in $40 \%$ of the malignant gliomas of children older than 3 years, a much higher rate than in the tumors of older adults, but comparable to that in young adults. ${ }^{12}$ Such tumors are known as secondary high-grade gliomas, because they contain p53 mutations, which are present in low grade gliomas, subsequently progress to high-grade gliomas accompanied by mutations of other tumor suppressor genes such as the retinoblastoma $(\mathrm{Rb})$ gene or phosphatase and tensin homology (PTEN) gene. ${ }^{13}$ Overexpression of p53 in malignant gliomas in children, found in one third of tumors examined, and not always in association with a p53 mutation, was strongly associated with a poor prognosis, independent of tumor histology and clinical prognostic features. ${ }^{14}$ Adult high-grade gliomas referred to as de novo (primary) malignant gliomas do not show p53 mutations or overexpression, but rather 
tend to show amplification of the epidermal growth factor receptor (EGFR) gene or inhibitor of cyclin-dependent kinase 4 tumor suppressor gene as probable mechanisms of tumorigenesis. However, in high grade gliomas in children, EGFR amplification is rarely seen, although overexpression of EGFR is very common. ${ }^{15}$ Because of these differences in the genetic alterations between pediatric and adult pediatric brain tumors, agespecific analysis will be essential in future studies.

For medulloblastomas, genetic markers which have correlated with prognosis in small studies include Trk C (neurotrophin 3 receptor) expression, of which a high level correlated with good outcome ${ }^{16}$ and C-myc oncogene amplification, which had very high predictive power of a poor prognosis, though it was only present in $7 \%$ of the tumors tested. ${ }^{17}$ Other genetic alterations found in medulloblastomas, which may have prognostic predictive value are those of the N-Myc and ERRB2 oncogenes, ${ }^{18}$ loss of caspase- 8 expression, ${ }^{19}$ and mutations of several signal transduction pathways including the PTCH1/'Sonic Hedgehog", Wingless" (WNT/WG)/ beta catenin, and PDGF-a/RAS/MAP tyrosine kinase pathways. ${ }^{20,21}$ At this time, the best independent predictor of medulloblastoma outcome may be the overall pattern of gene expression. DNA microarray gene expression analyzed in tumor tissue from a large cohort of medulloblastoma patients showed that clinical outcome is predicted by the profile of gene expression, and is a better predictor than the expression or amplification of any single gene or any single gene mutation. ${ }^{22}$ The results of the gene expression patterns and other genetic alterations are now being validated in the current Childrens Oncology Group (COG) protocols for medulloblastoma, and may complement clinical and histologic criteria for risk-stratification in future studies.

Mutation of the gene INI-1 on chromosome 22, has recently been detected in a high percentage of patients with the intracranial tumor, the atypical teratoid/rhabdoid tumor (AT/RT). ${ }^{23}$ These tumors, which predominate in young children, are frequently mistaken for medulloblastoma or primitive neuroectodermal tumors (PNET) based on histological appearance, but are much more aggressive with a worse prognosis and require more intensive treatment. Therefore, the malignant tumors of children less than 3 years of age should probably be tested for this mutation.

\section{THERAPEUTIC MODALITIES}

Surgery. Surgery is the initial treatment for the majority of children with brain tumors. A surgical resection that is as extensive as possible is important for the best long-term survival with most tumors. For some, such as low grade cerebellar astrocytomas, a complete surgical resection is curative. For others, like ependymoma and medulloblastoma, maximal resection confers a better prognosis for survival, even though additional adjuvant therapy, such as chemotherapy and/or radiation therapy, is also required. The extent of resection has to be balanced between the benefit to be gained and the risk of injury to critical neuroanatomic structures. Newer radiographic and electrophysiologic methodologies permit a surgical approach to some previously "unresectable" tumors, with a better margin of safety. Functional MRI allows preoperative determination of the proximity of the tumor to eloquent brain regions. Image-guided stereotactic techniques now permit intra-operative tumor localization and clarify the tumor's relationship to critical structures. Various types of intra-operative electrophysiologic monitoring also optimize the degree of resection while minimizing risk for neurological morbidity. These include the measurement of evoked motor and sensory responses during surgery so that the extent of resection can be limited if critical loss of function is encountered, and electrical corticography, which involves placing subdural electrodes on the surface of brain for "mapping" of vital regions before tumor resection is undertaken. ${ }^{24}$

Radiation therapy. Radiation therapy (RT) was the first adjuvant treatment for brain tumors, and was initially applied to the treatment of adult gliomas and pituitary tumors in the early 1900s. It remains very effective therapy for many malignant pediatric brain tumors, contributing substantially to duration of survival and the chance for cure. RT for pediatric brain tumors is usually delivered either to the primary tumor site (involved field) or to the entire craniospinal axis for tumors such as medulloblastoma with an underlying tendency to metastasize throughout the central nervous system.

With the improved survival of children with brain tumors over the last two decades, in part due to advances in the delivery of RT, recognition of its adverse effects on the developing nervous system has increased. Radiation-mediated neurologic "late effects" include the potential for cognitive impairment, CNS vasculopathies and stroke, neuroendocrine deficits, and increased risk for secondary malignancies in the radiation field, all of which are magnified in younger children. ${ }^{25}$

The use of RT for tumors is predicated on a differential effect on tumor vs. normal tissue, the therapeutic ratio. ${ }^{26}$ Substantial improvements in RT for brain tumors have arisen from development of technologies that optimize this ratio by maximizing therapeutic dose to tumor while minimizing dose to surrounding normal brain. Threedimensional conformal RT and intensity-modulated RT have come about through better computer modeling capabilities linked to improved imaging and the delivery of RT through multiple portals. This permits more precise tailoring of RT dose to irregular tumor contours and reduces its administration to surrounding brain. ${ }^{27}$ The detrimental effects of RT are now somewhat decreased 
with the widespread implementation of these technologies.

Stereotactic radiosurgery and the Gamma knife are RT approaches that entail delivery of a single high dose of radiation using a large number of intersecting beams, and facilitated by precise neuroimaging and cranial immobilization. These methods have been useful for the treatment of unresectable pediatric brain tumors which are small and well circumscribed, and where the ablation of normal tissue very close to the target does not cause unacceptable toxicity. ${ }^{28}$ Another recent experimental approaches to improve the efficacy of RT is the use of biologic response-modifiers that increase tumor sensitivity to radiation or decrease radiation resistance. Pretreatment with chemotherapeutic agents, such as carboplatin and gemcitibine were found to enhance the effect of irradiation on tumor cell killing. ${ }^{29,30}$

Chemotherapy. Chemotherapy for the treatment of pediatric brain tumors was initiated in the 1970s and its use is still driven by the relatively poor prognosis of many of these neoplasms, as well as by concerns about the detrimental adverse effects of RT on the developing brain. With conventional chemotherapeutic agents alone or in combination with RT, there has been considerable improvement in the outcome of children with brain tumors, including medulloblastoma, malignant astrocytoma, low grade optic pathway glioma, and malignant tumors in infants. A pivotal factor in improvement in the treatment of may pediatric brain tumors, is the high level of participation in trials conducted through multiinstitution consortia such as the Children's Cancer Group (CCG) and Pediatric Oncology Group (POG), now merged as the Children's Oncology Group, The International Society of Paediatric Oncology (SIOP) and the Pediatric Brain Tumor Consortium. Participation in such clinical trials is critical for therapeutic advances to continue. Specific chemotherapy regimens are discussed below.

Investigational therapies: Overview. Identification of molecular disparities between brain tumor cells and normal cells has opened the way for a number of therapeutic strategies that exploit these differences. Unique properties of tumor cells may permit the targeting of tumor cells for elimination, while sparing normal cells. Such "targeted" therapies inhibit tumor growth by various approaches, including immunotherapy, inhibition of signal transduction pathways, anti-angiogenic therapy, and regulation of gene expression.

Immunotherapy. Advances in basic immunological research have stimulated interest in immunotherapy as a modality for targeted treatment of brain tumors. Two promising immunotherapeutic approaches are the development of various tumor vaccines, and of monoclonal antibodies or other ligands for tumor-specific receptors that can be linked to tumor toxins or radioisotopes.
Vaccine therapy employs strategies for activating the immune system to overcome the tolerance that appears to develop to cancer cells. Dendritic cells, the most potent antigen-presenting cells, can be sensitized with various forms of tumor antigen to induce stronger cell-mediated active immune responses that inhibit the growth of human gliomas in both adults and children. ${ }^{31,32}$ In animal models, T-cell-activating cytokine genes have been introduced into autologous irradiated tumor cells ex-vivo, and these cells are then used for vaccination to override tumor-induced immunosuppression. ${ }^{33}$

Monoclonal antibodies to a number of tumor growth factors or to growth factor receptors, such as epidermal growth factor (EGF) and its receptor (EGFR), among others, have tumor cell anti-proliferative activity in vitro and in animal xenograft models. Results from ongoing phase I and phase II brain tumor clinical trials using armed radio-labeled monoclonal antibodies, targeting various tumor-specific antigens are somewhat encouraging, with stabilization of disease and prolonged survival, although many challenges to its safe and effective application for brain tumors remain. ${ }^{34}$

Ligands for tumor-specific receptors may also effectively target brain tumors. Transferrin receptors are much more numerous on both glioma and medulloblastoma tumor cells than on normal cells. In in vivo animal models, transferrin conjugated to Diphtheria selectively binds to and kills tumor cells. ${ }^{35}$ This methodology has shown promising results in an adult clinical trial, with significant responses of recurrent malignant gliomas after intratumoral injection of the transferrin/diphtheria toxin conjugate. ${ }^{36}$ It is currently being tested in recurrent supratentorial high-grade gliomas in children.

Inhibition of tumor signal transduction pathways. Another targeted therapy involves the inhibition of specific molecular pathways important for tumor growth. Tumor cell growth factor receptors are linked through complex downstream molecular pathways involved in cellular proliferation. Some monoclonal antibodies directed against such receptors can inhibit these signal transduction pathways and promote tumor cell apoptosis. Other small molecule inhibitors directed against tumor cell receptor tyrosine kinases may be important tumorigenic mechanisms in some medulloblastomas and highgrade gliomas. These include gefitinib (Iressa) targeting the epidermal growth factor receptor (EGFR) tyrosine kinase, ${ }^{13}$ imatinib mesylate (Gleevec), targeting the platelet-derived growth factor-alpha receptor (PDGFaR) tyrosine kinase, ${ }^{21}$ and erlotinib (Tarceva), targeting the oncogene ERBB2 receptor tyrosine kinase. ${ }^{13}$ These small molecule inhibitors have entered clinical brain tumor trials for adults and children.

Agents directed at downstream targets in other tumor proliferation signal transduction pathways are also in development, including those directed against the PTCH/ 
Sonic Hedgehog pathway, important in some medulloblastomas. ${ }^{37}$ Inhibitors of the PTEN oncogene-activated phosphatidylinositol-3 kinase/ras/AKT and downstream target, mammalian target of rapamycin (mTOR) pathway (PTEN/PI3K/ras/AKT/mTOR pathway), such as rapamycin (Sirolimus) and rapamycin derivative (Everolimus) are important in the tumorigenesis of some highgrade gliomas and are in adult clinical trials. ${ }^{13}$ Farnesyl transferase inhibitors, such as tipifarnib (Zarnestra), which impair processing of proRas and inhibit the Ras signaling pathway, are also now in clinical trials for pediatric and adult brain tumors. ${ }^{13}$

Anti-angiogenic therapy. Tumor-induced angiogenesis is a process discovered to be an important mechanism supporting tumor growth in several models. ${ }^{38} \mathrm{An}$ giogenic factors such as $\alpha$ and $\beta$ fibroblast growth factors (FGF), vascular endothelial growth factor (VEGF), and angiogenin, among others, are elaborated by tumor or mobilized from extracellular matrix or macrophages drawn to tumor under the influence of hypoxia, and facilitate angiogenesis in a number of ways. ${ }^{38}$ Antiangiogenic agents have diverse mechanisms of action; they may inhibit endothelial cell proliferation, inhibit specific angiogenic factors, target vascular smooth muscle or integrin signaling, or inhibit matrix metalloproteinases. Some have produced tumor regression and cure in animal tumor xenograft models. ${ }^{39}$ Phase I clinical trials of anti-angiogenic agents are underway. ${ }^{38}$ Cilenglitide (EMD 121974), an anti-angiogenic integrin receptor antagonist in preclinical trials, ${ }^{40}$ is currently being evaluated in a phase I trial for children with recurrent brain tumors. Preliminary results suggest some efficacy for brain tumors; a likely future strategy will be to combine anti-angiogenic drugs with other adjuvant therapies.

Gene therapy. Increased understanding of the molecular events in tumor development may permit the application of gene therapy strategies to the treatment of both adult and pediatric brain tumors. Gene therapy offers the hope of sensitizing tumor cells to systemic therapies, replacing defective tumor genes, and blocking mechanisms of tumor progression. This may be accomplished using various vector and delivery systems. Types of vectors most suitable for tumor gene therapy include retroviral, herpes, and adenoviral and adeno-associated vectors. ${ }^{41}$ Retroviral vectors preferentially infect rapidly dividing cells which, in theory, would make them good candidates to treat malignant brain tumors; goals include maximizing transfection of tumor cells and minimizing transduction of normal cells.

Delivery of the transfected gene to the tumor is achieved either by direct intra-parenchymal installation or by intravascular delivery. Intra-parenchymal delivery provides more accurate localization to the tumor, but encounters problems of failure of diffusion of the gene to all of the tumor cells. Intravascular delivery to the brain has the obvious difficulties of traversing the blood-brain barrier, possibly overcome by disruption of the barrier at the time of delivery, as well as the lack of localization and greater possibility for interaction with non-target cells, such as endothelial cells.

Several gene therapy strategies for brain tumors are currently being applied, mainly to adult populations, and may have potential for application to the treatment of pediatric brain tumor in the future; These include prodrug activation, tumor suppressor gene therapy, and antisense gene therapy. ${ }^{41}$

Prodrug activation. Prodrug activation is also termed "suicide therapy," in which a vector carrying a gene coding for a protein that sensitizes cells to a specific drug is delivered to a tumor. The largest experience with this type of therapy uses the herpes simplex virus thymidine kinease-gancyclovir regime to treat malignant gliomas. In this model, a modified herpes virus vector expressing the enzyme, thymidine kinase, after stereotactic intratumoral injection, is preferentially taken up and encorporated by rapidly dividing tumor cells. ${ }^{42}$ The patient is given gangcyclovir systemically, which is then converted by the thymidine kinase to a toxic metabolite, killing the tumor cells. Unfortunately, this regimen, which has been tried in children with high-grade gliomas, has so far met with limited clinical success, mainly because of poor transfection efficiency of tumor cells. ${ }^{43}$ There are ongoing studies with several other prodrug activator proteins and their corresponding prodrugs that may provide more powerful combinations for gene therapy in the future. ${ }^{44}$

Tumor suppressor gene therapy. Tumor suppressor genes code for proteins that inhibit cell growth. The loss of tumor suppressor function by mutation or deletion of a tumor suppressor gene has been implicated as the mechanism of oncogenesis of glioma and medulloblastoma brain tumors. ${ }^{45}$ Tumor suppressor gene therapy replaces the missing or mutated tumor suppressor protein, theoretically restoring the normal pre-tumor cell phenotype. Preclinical animal studies applying this therapy for the p53 and PTEN tumor suppressor genes encouraging, but tumor heterogeneity in human tumors, with cells in the same region expressing different genes, is an obstacle to using this paradigm, clinically. ${ }^{46}$

Antisense gene therapy. Antisense gene therapy prevents the expression of proteins that facilitate tumor progression. Knowledge of the oncogene DNA sequence responsible for a protein important for tumorigenesis, allows design of a vector with the "antisense" gene that will produce a single-stranded RNA molecule with a sequence complementary to the mRNA produced by the abnormal tumor target gene. When the antisense gene is taken up and expressed in the tumor, the complementary RNA produced then binds to mRNA of the tumor target gene, hindering the ribosome apparatus, preventing mRNA translation and synthesis of the pathogenetic pro- 
tein. Using this method, several genes have been inhibited in animal models, such as urokinase plasminogen activator receptor and cathepsin B, resulting in some tumor regression. ${ }^{47}$ This methodology should have several advantages over other gene therapy methods, including not being hindered by low transfection rates and having the possibility of inhibiting multiple pathogenetic genes within the same vector. A disadvantage is the relative instability of the single stranded antisense RNA.

\section{COMMON PEDIATRIC BRAIN TUMORS AND THERAPY ADVANCES}

\section{Primitive neuroectodermal tumor (PNET)/ medulloblastoma}

Central nervous system (CNS) PNETs are a group of malignant primary brain neoplasms composed of primitive undifferentiated neuroepithelial cells with aggressive embryonal characteristics, sometimes with evidence of differentiation along neuronal, glial or ependymal lines. The term PNET was first used to describe supratentorial cerebral hemisphere tumors, but Rorke later proposed that medulloblastoma was the infratentorial (cerebellar) counterpart of these tumors, which she thought should all be grouped together, based on their similar appearance, with small, round, blue undifferentiated-looking cells and presumed common pleuripotential neuroepithelial cell of origin. ${ }^{48}$ Though widely accepted, this is not a universal opinion, and while these tumors do have similarities in microscopic appearance and in their proclivity to metastasize throughout the CNS, supratentorial PNETs respond less well to therapy and have a poorer prognosis than their infratentorial/ medulloblastoma counterparts. For this reason they are assessed separately in most therapeutic studies, although the supratentorial PNETs are usually treated on the same protocols as are high-risk medulloblastomas. Recent significant advances made in identifying key molecular markers/gene expression patterns of theses tumors should help to resolve controversy about PNET classification and better stratify them for future therapy. ${ }^{22}$

Medulloblastoma, (infratentorial or cerebellar PNET), accounts for $20-25 \%$ of pediatric brain tumors, making it the most common intracranial tumor of childhood. ${ }^{49}$ In children, the tumor typically arises from the cerebellar vermis in the roof of the fourth ventricle into which it grows, filling the cavity and causing obstructive hydrocephalus. (Figure 1) Most children present with symptoms of increased intracranial pressure, including headache, vomiting, irritability or lethargy, and sometimes with symptoms due to involvement of local structures, such as ataxia, head tilt or cranial nerve palsies. Medulloblastoma have a high propensity to CNS dissemination. This dictates that even after a total surgical resection, some type of adjuvant therapy to the entire neuroaxis is
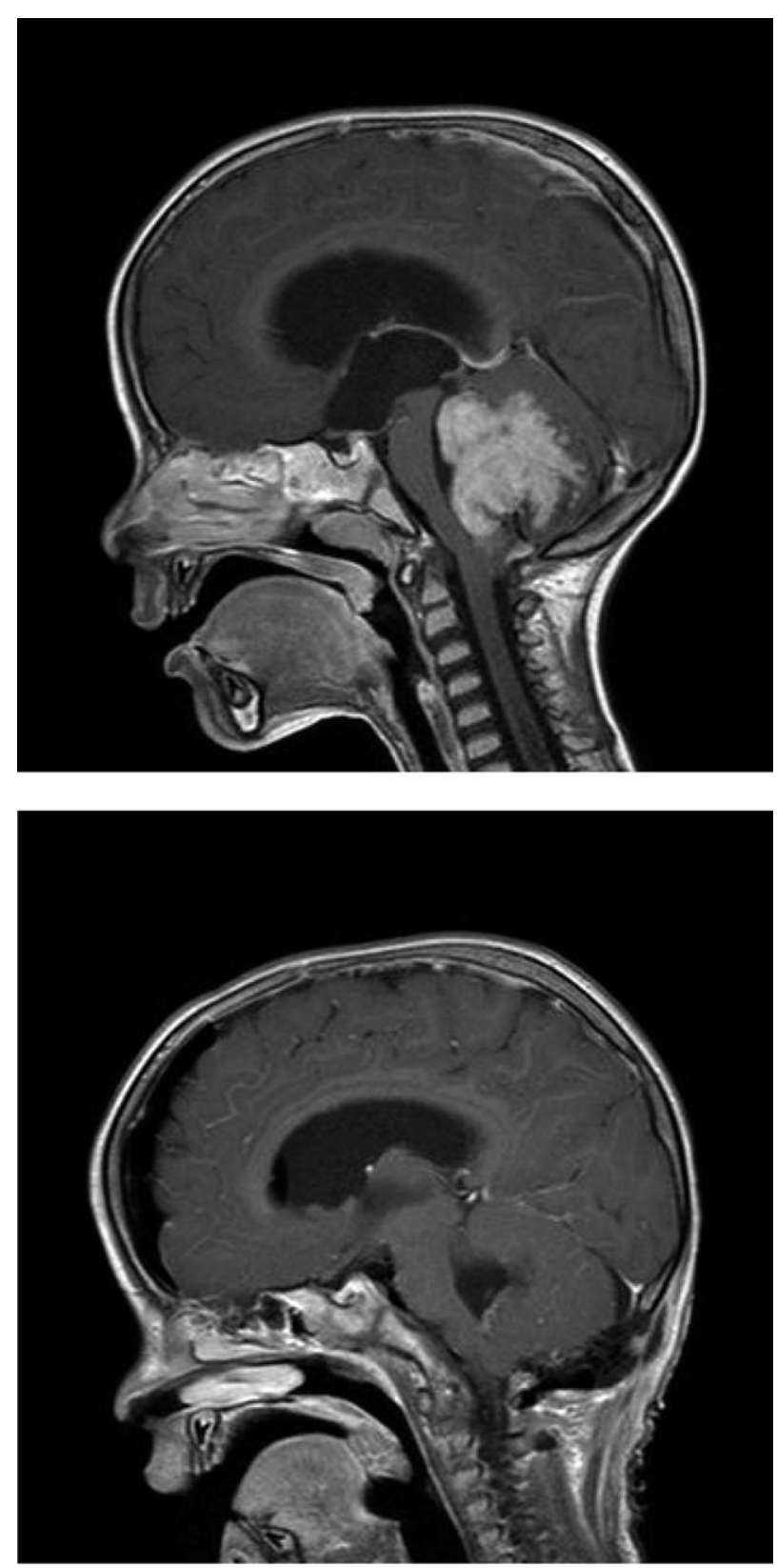

FIG. 1. Sagittal T1-weighted brain MRI, after gadolium administration: a. posterior fossa medulloblastoma before surgery, demonstrating homogeneous enhancement, filling the fourth ventricle and causing obstructive hydrocephalus. b. post-operative image 24 hours after surgery, confirming gross total resection of the tumor.

required to treat what is very likely to represent invasive multicentric disease.

Contemporary staging of medulloblastoma depends on both a surgical and post-operative MRI estimate of residual tumor at the primary site, on pre-operative or post-operative MRI evaluation of the brain and total spine for metastatic disease, and on the post-operative cytologic evaluation of lumbar CSF. Children with medulloblastoma stratify as high-risk for relapse if they have either metastatic disease in brain, spine or CSF, or 
have $>1.5 \mathrm{~cm}^{2}$ residual tumor at the primary site. ${ }^{18}$ This risk-stratification scheme currently dictates the therapy regimen employed, in which high-risk medulloblastomas are grouped with supratentorial PNETs because they are at somewhat similar higher risk for recurrence.

Supratentorial PNETs, including pineal regions PNETs, also occur predominantly in early childhood, and are diagnosed by 10 years of age in $80 \%$ of patients. $^{50}$ They constitute only about $3 \%$ of all pediatric brain tumors. Cerebral PNETs may present with signs of increased intracranial pressure, usually from the mass of a large tumor, and/or localizing signs dependent on tumor location. Pineal region PNETs, like other pineal region tumors, often present with hydrocephalus due to compression of the cerebral aqueduct, or with Parinaud's syndrome (upgaze paralysis, absent pupillary reactivity to light, and convergence or retractory nystagmus) from tectal midbrain compression. Supratentorial PNETs also have a propensity to CNS dissemination, and therapy for these tumors, as for medulloblastomas, includes surgery, neuroaxis irradiation, and chemotherapy. The survival rates for children with supratentorial PNETs are poorer than for those with medulloblastoma, but they have been grouped with high-risk medulloblastomas for treatment stratification.

Medulloblastoma/PNET therapy. Surgical resection of the tumor is first line of therapy for medulloblastoma/ PNET. Surgery plays an important immediate role in reducing tumor burden, and often in opening the ventricular system, re-establishing normal CSF flow and ultimately obviating shunt placement. Moreover, among medulloblastoma and supratentorial PNET patients with no metastatic disease, there is evidence suggesting that extent of residual tumor after surgery correlates with outcome ${ }^{51,52}$ However, surgical resection, alone, cannot cure medulloblastoma, and radiation therapy to only the primary tumor site, or at a dose of $<5000 \mathrm{cGy}$ to the primary site, is associated with poor outcomes. Thus, for some time, standard therapy for medulloblastoma after surgical resection, had been craniospinal irradiation (35-36 Gy) and a boost to the posterior fossa (54-56 Gy), with 5-year progression-free survival (PFS) of about $60 \% .{ }^{18}$ Although this approach had a major impact on survival, it was far from satisfactory, considering the significant morbidity of craniospinal RT, death from progressive disease in 30-40\% of average-risk patients, and less than $30 \%$ survival of those with high-risk disease. Supratentorial PNETs may have an even poorer prognosis after surgery and RT, with a 5-year PFS in one series, of only $12 \% .^{50}$

High-risk medulloblastoma/PNET therapy. All these factors were an impetus for medulloblastoma/ PNET therapy trials combining RT and chemotherapy. Several trials demonstrated efficacy of adjuvant chemotherapy for high-risk metastatic or residual disease. ${ }^{53-55}$
Especially promising results were reported for high-risk medulloblastoma patients using an adjuvant regimen of cisplatin, $\mathrm{CCNU}$ and vincristine after standard neuroaxis irradiation, with a 5-year PFS of $85 \% .^{56}$ Patients who were high-risk due to residual disease did better than those with metastatic disease, with $90 \%$ 5-year survival vs. $67 \%$, respectively. Another approach to high-risk medulloblastoma/PNET is the administration of highdose chemotherapy after craniospinal irradiation. A small international consortium treated 19 high-risk medulloblastoma/PNET patients after RT, with 4 tandem cycles of high-dose chemotherapy with stem cell support, and reported 84\% 2-year PFS from the start of radiation therapy. ${ }^{57}$

High-risk supratentorial PNETs, generally, have not done as well as high-risk medulloblastomas. Patients with these tumors treated on the cisplatin/CCNU/vincristine regimen, with craniospinal RT up-front, fared more poorly, with 37\% 5-year PFS compared with $67 \%$ for high-risk medulloblastoma. ${ }^{58}$ Some studies have demonstrated a benefit from chemotherapy for supratentorial PNETs. Dirks et al showed a trend to longer survival in those supratentorial PNET patients who received chemotherapy vs. those who did not. ${ }^{50}$ Infants with non-pineal PNETs treated on the "Baby POG" studies had very good 5-year PFS of 55\%, but with no benefit for pineal PNET $^{25}$ Recently completed CCG trials for high risk PNET/medulloblastoma studied the use of further doseintensification of chemotherapy in 3 tandem cycles, with stem cell support after RT, or of chemoradiotherapy using carboplatin as a radiosensitizer for high-risk medulloblastoma/PNET. The results of these studies are pending.

Average-risk medulloblastoma therapy. The improved outcome of high-risk medulloblastoma patients gave momentum to efforts aimed at minimizing treatment-related neurotoxicity in children with average-risk medulloblastoma by reducing craniospinal radiation dose and supplementing the treatment regimen with chemotherapy. Previous attempts at neuroaxis radiation dosereduction without other adjuvant therapy, had failed when the dose was reduced to $18 \mathrm{~Gy}$, or even to 24 Gy. ${ }^{59,60}$ Several subsequent studies showed outcomes of at least $70 \%$ PFS with the addition of chemotherapy to craniospinal axis dose of $24 \mathrm{~Gy} .{ }^{61,62}$ From a pilot study using the regimen of cisplatin/CCNU/vincristine after 24 Gy RT dose to the neuroaxis, children with average-risk medulloblastoma had a 3-year PFS of $85 \% .{ }^{56}$ In the most recent COG study, after treatment with 24 Gy craniospinal RT and concurrent weekly vincristine, children with average-risk disease were randomized to two different adjuvant chemotherapy regimens (cisplatin/CCNU/vincristine vs. cisplatin/cyclophosphamide/vincristine), each of which resulted in 4-year PFS rates of greater than $80 \%$. $^{63}$ 
Infant medulloblastoma therapy. Infants and very young children with medulloblastoma have poorer survival than older children when treated with standard RT, and even more significantly, they sustain much greater treatment-related neurotoxicity. Therefore, in the mid1980s, Duffner et al., ${ }^{25}$ through the Pediatric Oncology Group, developed and implemented a novel approach in which prolonged postoperative multi-agent chemotherapy was given in an attempt to delay radiation therapy for infants less than 3 years of age with medulloblastoma (other infant malignant brain tumors were also included). This approach proved to be successful in delaying RT for as long as 2 years in those youngest at diagnosis, and even in reducing the dosage of neuroaxis irradiation to 24 Gy in children with no evidence of disease after chemotherapy. Although the overall survival rate of $40 \%$ at 5 years was poorer than for older children with average-risk medulloblastoma who receive RT upfront, among infants who had a surgical gross total resection (GTR), 5-year survival was $60 \%$, and in those with no metastases at diagnosis and a GTR, it was $69 \%$, comparable to that average-risk patients treated initially with RT. Children's Cancer Group conducted an infant brain tumor study that similarly delayed RT in infants $<3$ years, using prolonged " 8 -in-1" chemotherapy, but with a 3 -year PFS of only $22 \%$, (likely because this chemotherapy was less intensive), although most of these longterm survivors, in fact, never received any RT. ${ }^{64}$

A different approach with the goal of deferring RT until relapse was pursued in several small trials using various different chemotherapy regimens; outcomes ranged from 5 -year survival of $67 \%$, to 2-year survival of $43 \%$. $^{65-67}$ The results of the French Oncology Group (SFOP) study of children $<5$ years old treated for 16 months with multiagent chemotherapy and deferring RT until relapse, emphasized the importance of radical surgery; the 5-year PFS of the 34 children with no metastatic disease (M0 stage) and GTR was $41 \%$ vs $0 \%$ for those with a subtotal resection. ${ }^{68}$ Taken together, these studies suggest that infant medulloblastomas are responsive to chemotherapy, and that a gross total resection and M0 staging are significant prognostic factors. Such infants could reasonably be treated with relatively-prolonged chemotherapy, withholding RT until relapse; those with metastatic or residual tumor require a different approach.

A recently conducted trial, CCG 99703, tested an hypothesis that intensifying the chemotherapy while deferring RT, would improve outcome for infant medulloblastoma patients $<3$ years of age. This study employed three cycles of chemotherapy similar to the initial "Baby POG" regimen, followed by three cycles of dose-intensified (but subablative) chemotherapy, with carboplatin and dose-escalation of thiotepa, supported with autologous stem cells collected after the initial cycles of chemotherapy; no RT was prescribed or specifically recom- mended. The study closed to accrual in late 2004 so that outcome results are pending.

Also, because of concern for neurotoxicity of RT in young children, the use of high-dose ablative chemotherapy with autologous bone marrow transplant (ABMT) or stem cell rescue for children with recurrent or newly diagnosed tumor is being explored. In view of the chemo-sensitivity of medulloblastomas there have been preliminary studies in which a small number of newlydiagnosed infants were successfully treated in consolidation with high-dose chemotherapy followed by bone marrow or stem cell support; this approach may have a larger role in treating young children, as it may for patients who relapse after standard therapy. ${ }^{69,70}$

Because of the high risk for development of neurocognitive deficits and the moderate success using chemotherapy, there has been little enthusiasm for administering RT, especially in a craniospinal volume, to infants and children $<3$ years of age. However, the possibility of using RT for local tumor control is being re-considered for infants, in view of the availability of the newer focused or 3-D conformal radiation. This approach is currently being used for infants with M0 medulloblastoma in COG study 9934; infants receive 3-D conformal RT after multiagent induction chemotherapy (and a second surgery for residual after chemotherapy), followed by 8 additional months of maintenance chemotherapy. Moreover, this conformal approach is being applied to primary site radiation therapy for average-risk medulloblastoma in older children, also aimed at reducing the neurotoxicity of brain irradiation. The methodology facilitates the accurate delivery of the tumor bed-radiation boost, with significant reduction in the radiation scatter to normal brain structures including the cochlea and auditory nerve in the posterior fossa, as well as to the diencephalon and other portions of supratentorial brain. Two single institution pilots have already demonstrated safety of this technique, with no increased posterior fossa recurrences among patients. ${ }^{71,72}$ These findings are being validated in the current COG average-risk medulloblastoma study, which randomizes patients to conformal tumor bed with margins volume vs standard posterior fossa volume.

Medulloblastoma/PNET investigational therapy. Better therapy for medulloblastomas undoubtedly will have its basis in clarification of tumor molecular biology, and could evolve in at least two ways. Improved understanding of the molecular signature of individual tumors will help in determining prognosis and more accurate tumor risk-stratification, permitting children at lower risk for recurrence to safely receive less toxic therapy, and reserving more intensive treatment for those at higherrisk. Knowledge of the molecular defects critical in tumorigenesis could also provide the means to use them as targets for novel therapeutic approaches. 
A number of studies have identified several possible molecular traits that could serve as prognostic factors, as well as potential targets for therapy of medulloblastoma. Among these are the amplification or overexpression of several oncogenes, including ERBB2, C-Myc, and NMyc, ${ }^{18}$ loss of caspase- 8 expression, ${ }^{19}$ and mutations in several other signal transduction pathways including the PTCH1/"Sonic Hedgehog" pathway, "Wingless" (WNT/ WG)/beta catenin pathway, ${ }^{37}$ and platelet-derived growth factor-alpha (PDGF-a) and RAS/MAP tyrosine kinase pathway. ${ }^{21}$ The best outcome predictor, to date, appears to be tumor gene expression profiling. A pilot study of medulloblastoma DNA microarray gene expression was able to demonstrate that clinical outcomes of children with medulloblastoma was highly predictable on the basis of the gene expression profile of their tumors at diagnosis, and independent of clinical or other criteria. ${ }^{22}$ The prognostic accuracy of any of these molecular markers in medulloblastoma is not yet firmly established, as they have all been evaluated in somewhat underpowered studies or have included heterogenous patient groups. However, validation of the most promising of these markers is ongoing in current COG and other international consortia medulloblastoma studies.

Understanding mechanisms of tumorigenesis for future molecular classification and prognosis is also the first step in the development of molecular-targeted therapies. Specific small molecule tyrosine kinase inhibitors could prove effective against targets in some medulloblastoma (and other brain tumors). These include imatinib mesylate (Gleevec), a PDGFa/RAS/MAP tyrosine kinase inhibitor, ${ }^{21}$ Erlotinib (Tarceva), which inhibits the oncogene, ERBB2 tyrosine kinase, and Iressa (gefitinib), which inhibits the EGFR tyrosine kinase. ${ }^{13}$ Moleculartargeted therapies still in pre-clinical evaluation include cyclopamine, a plant-derived teratogen that suppresses the membrane protein, SMO, which is activated and stimulates cell proliferation when there are mutations in the PTCH/Sonic Hedgehog pathway of some medulloblastomas; ${ }^{20}$ cyclopamine has side effects that limits its clinical application, but other agents which inhibit this pathway are also under development.

The retinoid, cis-retinoic acid, is another therapeutic agent soon to be evaluated in a randomized fashion in the upcoming COG protocol for high-risk medulloblastoma/ PNET tumors. Retinoids mediate apotosis in medulloblastoma cells in vitro, and suppress tumor growth in xenograft models. ${ }^{73}$

\section{Gliomas/Astrocytomas}

Gliomas, which are predominantly astrocytomas, make up the largest fraction of pediatric primary brain tumors, representing between $45 \%$ and $60 \%$ of tumors in most series. ${ }^{49}$ The majority are low-grade astrocytomas (35-50\% of all pediatric brain tumors), in contrast with trends in adults in whom high-grade astrocytomas and glioblastoma are the most common tumors. In the posterior fossa, low-grade astrocytomas are almost always pilocytic astrocytomas, usually in the cerebellar hemispheres, and constitute about $12-15 \%$ of pediatric brain tumors. $^{49}$ Supratentorial low grade astrocytomas (30-35\% of pediatric brain tumors) arise in the cerebral hemispheres (20-25\%) or in the midline as optic pathway or hypothalamic gliomas (10\%). Only about $10-12 \%$ of pediatric brain tumors are high grade astrocytomas, either anaplastic astrocytoma or glioblastoma multiforme, and nearly all in supratentorial locations.

Low-Grade Gliomas. Pilocytic astrocytomas are the second most-common tumor in the posterior fossa after medulloblastoma (12-15\% of pediatric brain tumors), and when treated with surgical resection alone, have the best prognosis of any pediatric intracranial neoplasm. Cerebral low-grade gliomas can be pilocytic astrocytomas, but are more often non-pilocytic gliomas of various types; they have greater propensity to infiltrate surrounding brain, which makes performing a complete resection more difficult. Nevertheless, among patients who undergo total resection, 10-year survival rates exceed $80 \%$ for hemispheric cerebral tumors, ${ }^{74}$ and $90 \%$ for cerebellar tumors. ${ }^{3,75}$ For tumors that progress following surgery, radiation therapy is beneficial, ${ }^{76}$ although there is less experience using it in this setting than there is for the usually unresectable deep midline low grade gliomas discussed below.

In contrast to cerebellar or cerebral low grade gliomas, the midline optic pathway/hypothalamic gliomas (OPG), which constitute $3-5 \%$ of pediatric brain tumors and are also frequently low-grade pilocytic astrocytomas, are rarely amenable to complete resection, by virtue of their infiltration of critical structures. These tumors of the visual pathways may involve one or more optic nerves, the optic chiasm (where they may be exophytic into the third ventricle or hypothalamus), the optic tracts, optic radiations, and the occipital cortex (Figure 2). They predominate in young children ( $75 \%$ in those $<10$ years) and are associated with Neurofibromatosis Type 1 (NF 1); $20-30 \%$ of OPGs are in NF 1 patients. ${ }^{77}$ In lesions that are exophytic from the chiasm into third ventricle or hypothalamus, a subtotal resection may be possible, sometimes obviating a shunt in patients with hydrocephalus. ${ }^{78}$ However, for most of these tumors, if treatment is required, alternatives to surgery are necessary.

Although OPG neoplasms nearly always have lowgrade histology, their biologic behavior and growth characteristics, in vivo, vary tremendously. Good prognostic factors for stability after diagnosis include involvement only of visual structures and not of hypothalamus, older age of the child, and occurrence in a patient with NF1. ${ }^{78,79}$ The treatment of these tumors must be individualized; children with minimal and non-progressive 

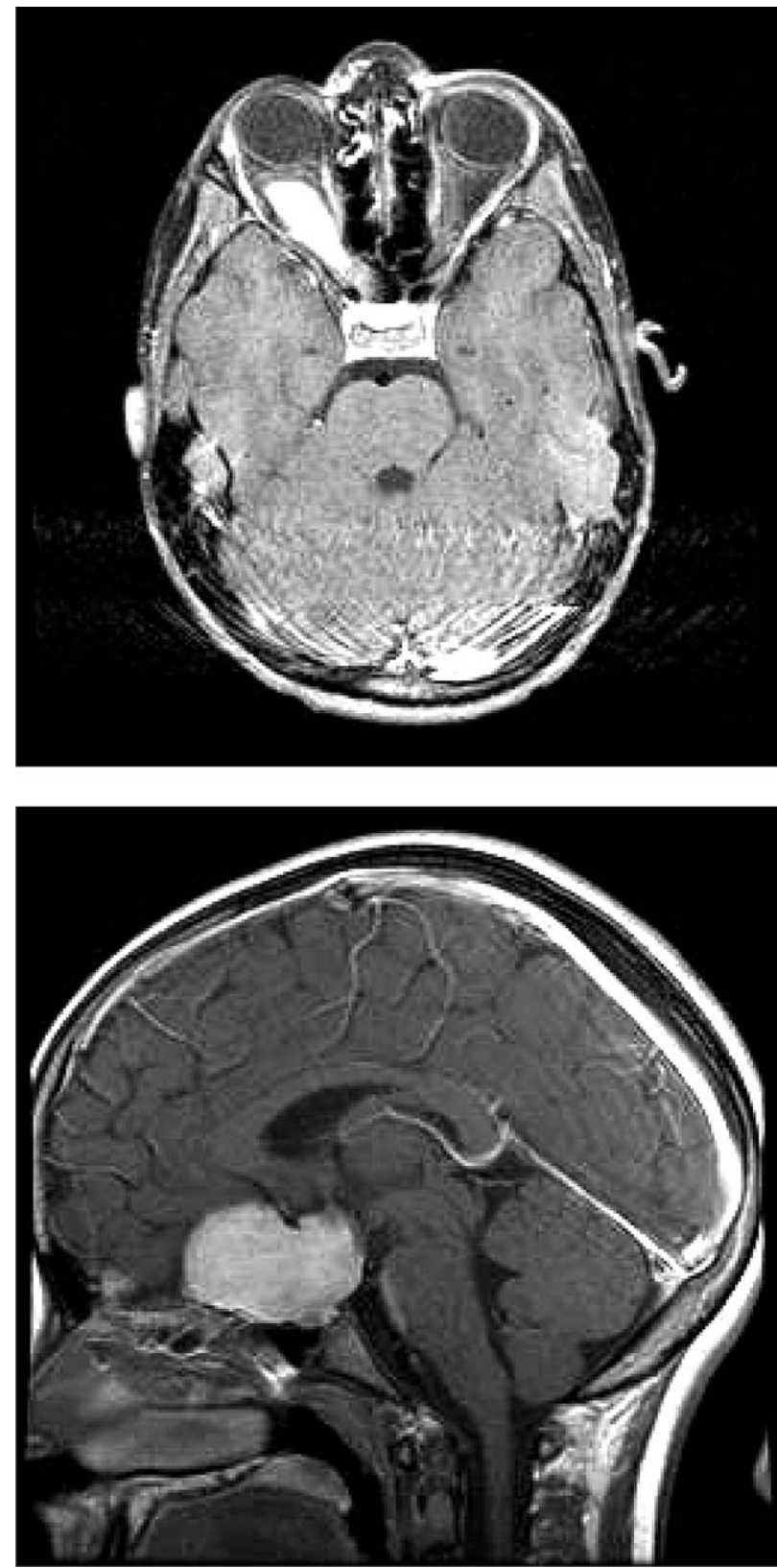

FIG. 2. Axial T1-weighted brain MRI after gadolinium administration, demonstrating enhancing right optic nerve glioma. $b$. Sagittal T1-weighted brain MRI of an enhancing optic nerve/ chiasm glioma that is exophytic into the hypothalamus.

symptoms and radiographic stability, are followed expectantly. Although radiation therapy had been the mainstay of treatment of these tumors, ${ }^{80}$ because of the association of radiotherapy with increased risk for neurocognitive and neuroendocrine late effects, especially in children younger than 5 years, ${ }^{81}$ currently, RT is usually withheld in favor of administering chemotherapy in an attempt to defer, if not obviate RT altogether. Several chemotherapy regimens including carboplatin alone, carboplatin/vincristine, and procarbazine/CCNU/ vincristine/6-thioguanine have been tried for incom- pletely resectable low-grade gliomas in any location, although the majority are OPG/hypothalamic gliomas. These pilot trials reported regression or stability of tumors in $75-90 \%$ of patients. ${ }^{82-84}$ At follow-up, children treated on the carboplatin/vincristine regimen before age 5 years, had a $75 \%$ 4-year PFS rate. ${ }^{85}$ The outcome of a recently-closed COG phase III randomized trial comparing the latter two of these regimens is pending.

Although there are no prospective randomized trials evaluating radiotherapy for low-grade gliomas in children, benefit was reported for 24 children with progressive optic chiasm gliomas, who had $88 \%$ 6-year PFS. ${ }^{80}$ When radiotherapy is indicated for the treatment of an OPG (or a low-grade glioma in any location), the current strategy of stereotactically-guided conformal radiotherapy is optimal. Results of two studies using conformal RT to treat children with low grade gliomas are encouraging (in 38 children, a 2-year PFS of $88 \%$; in 14 children, a 3-year PFS of $87 \%$ ). ${ }^{86,87}$

\section{High-Grade Glioma/Astrocytoma}

Malignant Pontine Gliomas. The majority of brainstem gliomas are malignant, diffusely infiltrative tumors centered in the pons, and are not resectable. They present with the triad of rapidly progressive cranial nerve deficits, long-tract signs and ataxia, but without hydrocephalus, at a peak age of 5-14 years. Taken together with this typical clinical history, their appearance, with diffuse enlargement of the pons on MRI, is diagnostic, and biopsy is no longer indicated. ${ }^{3}$ Unfortunately, the prognosis of these rapidly growing, highly malignant tumors is very poor. The foundation of treatment has been radiation therapy, but the median survival is less than one year. Attempts to improve survival using hyperfractionated RT ${ }^{88}$, or chemotherapy ${ }^{89}$ have not been successful. A current therapy strategy is the application of chemotherapeutic agents as radiosensitizers, to try to improve the outcome for these tumors. ${ }^{90}$

Supratentorial High-Grade Gliomas. Supratentorial high grade gliomas in children include mainly anaplastic (malignant) astrocytomas and glioblastoma multiforme, and comprise $10-12 \%$ of CNS tumors in children. These include cerebral hemispheric tumors, as well as deep midline thalamic tumors. ${ }^{49}$

Supratentorial High-Grade Glioma Therapy. Conventional treatment for cerebral high-grade gliomas has been maximal resection followed by involved-field radiation therapy. Greater extent of tumor resection has been shown to correlate with longer PFS and is the most important clinical prognostic factor for these tumors. ${ }^{91}$ Radiation treatment of high-grade gliomas in children has been part of all published treatment regimens of the last two decades, although the data supporting its prognostic value are derived mainly from adult studies. Evidence for improved outcome with adjuvant chemother- 
apy for high-grade gliomas in children is modest, but it is routinely used. From one phase III CCG 921 study of children with high-grade gliomas, the 5-year event-free survival (EFS) for those who received adjuvant chemotherapy with the nitrosourea-based regimen of CCNU/ vincristine/prednisone plus RT after surgery was $46 \%$, vs. $18 \%$ for those who received radiotherapy alone. The benefit of the chemotherapy was demonstrated in the 33 children with glioblastoma in whom the 5-year EFS was $42 \%$ for those treated with chemotherapy plus RT vs. $6 \%$ for those treated with RT alone, whereas the number of anaplastic astrocytomas in the study was too small to demonstrate an effect of chemotherapy. ${ }^{92}$ The other phase III study, CCG 945, for pediatric high-grade gliomas compared two chemotherapy regimens, the prior CCNU/vincristine/prednisone regimen vs. the eightdrugs-in-one-day regimen, for which the overall 5-year EFS rates of $26 \%$ vs. $33 \%$, respectively, did not differ. ${ }^{93}$ A phase II German trial for pediatric high-grade gliomas determined that the pre-radiation and post-radiation chemotherapy significantly benefited those patients who also had a gross total resection, with 5.2 year vs. 1.9 year median survival. ${ }^{94}$

Other chemotherapeutic agents, such as temozolomide, an orally administered alkylating agent, and irinotecan, a topoisomerase-I inhibitor have been tried for newly diagnosed high-grade gliomas with modest success. ${ }^{95}$ A very recently completed phase II COG trial used temozolomide administered daily, concurrent with radiation therapy, and then afterward, in monthly cycles. Other studies combining various agents are also ongoing or in development in the COG.

Supratentorial High-Grade Glioma Investigational Therapy. Some investigational approaches to treatment of high-grade gliomas with chemotherapy focus on circumventing mechanisms of drug resistance that develops to alkylating agents. One of the major mechanisms of resistance to the nitrosoureas is the overexpression of the cellular enzyme in tumor cells, $\mathrm{O}^{6}$ guanine alkylguanine alkyltransferase (AGAT), which is responsible for removing alkyl groups from the $\mathrm{O}^{6}$ position of deoxyguanosine and preventing DNA cross-links. ${ }^{96}$ The drug $\mathrm{O}^{6}$ benzyl guanine $\left(\mathrm{O}^{6} \mathrm{BG}\right)$ which has high affinity for AGAT, enhances the activity of nitrosoureas in vitro and in vivo. ${ }^{96}$ Several phase II trials with $\mathrm{O}^{6} \mathrm{BG}$ and temozolomide, which also has the AGAT drug-resistance mechanisms, are ongoing.

Because the blood brain barrier (BBB) may be an obstacle to delivery of effective chemotherapy to brain tumors, various tactics have been developed to circumvent this problem. One strategy has been the use of agents, such as mannitol, prostaglandins, histamine and bradykinin, capable of transiently disrupting the BBB for enhanced chemotherapy delivery. Most recently, promising results were reported from a preliminary study us- ing a bradykinin analogue, labridimil (Cereport) children with brain tumors to disrupt the BBB prior to administration of carboplatin. ${ }^{97}$ Convection-enhanced delivery is another new method of delivering tumor-targeted large molecule toxins directly into tumor through a surgicallyplaced catheter. Adult phase I trials using this methodology are currently underway to deliver recombinant chimeric proteins, such as interleukin-4, linked with a pseudomonas exotoxin. The tumor-targeted toxins are then taken up by glioma cells, causing cytotoxicity after internalization. ${ }^{98}$

Increased knowledge of the tumor biology and molecular traits of high-grade gliomas, just as with PNET tumors, points the way to their use as potential targets for therapy. One of the most common molecular alterations so far identified in high-grade gliomas involves the epidermal growth factor receptor (EGFR). Overexpression of EGFR is very common in pediatric high grade gliomas, ${ }^{15}$ although gene amplification, the most common abnormality in adult, so-called "de novo" (primary) glioblastomas, is rarely seen in high-grade gliomas in children. Amplification of the platelet-derived growth factor alpha receptor (PDGFaR) gene and signaling by the PDGFaR/RAS/MAP tyrosine kinase pathway have been demonstrated in adult glioblastoma and play a role in the tumorigenesis of some pediatric medulloblastoma. This molecular pathway appears not to be as important for most pediatric high-grade gliomas, although PDGFR gene amplification was found in one of 14 high-grade gliomas in a recent study. ${ }^{99}$ The phosphatidylinositol-3 kinase (PI3K)/ras/AKT pathway and downstream target, mammalian target of rapamycin (mTOR), mediates functions of cell survival and migration, for which the PTEN (phosphatase and tensin homology) gene is an important regulator. Mutations of the PTEN gene have been identified in $6 \%$ of pediatric malignant gliomas and $20 \%$ of glioblastomas. ${ }^{100}$ Alterations in the p53 gene are fairly common in pediatric high-grade gliomas. Mutations of p53 were found in $40 \%$ of malignant gliomas in children $>3$ years, similar to the rate seen in the tumors of young adults. However, overexpression of the p53 protein, found on one third of a series of uniformly-treated pediatric malignant gliomas, did not correlate with the presence of a mutation but did correlate with a poor prognosis. ${ }^{14}$

Small molecule inhibitors of several of these targets have been developed and are in early clinical trials for adult high-grade gliomas, including Iressa (gefitinib), targeting the EGF receptor tyrosine kinase, ${ }^{13}$ Gleevec (imatinib), targeting the PDGF receptor tyrosine kinase, ${ }^{21}$ and Sirolimus (rapamycin) and Everolimus (rapamycin derivative), targeting the PTEN oncogene-activated $\mathrm{PI} 3 \mathrm{~K} / \mathrm{ras} / \mathrm{AKT} / \mathrm{mTOR}$ pathway. ${ }^{13}$ Phase I trials of Iressa and Gleevec are ongoing for recurrent and newly diagnosed high-grade gliomas in children. Just as with 
TABLE 1. Common Pediatric Brain Tumors

\begin{tabular}{|c|c|c|c|c|c|c|}
\hline Tumor & Diagnosis & Stage/Grade & Surgery & Radiation Therapy & Chemotherapy (CHT) & Prognosis \\
\hline PNET/Medulloblastoma & $\begin{array}{l}\text { Brain MRI } \\
\text { Histology }\end{array}$ & $\begin{array}{l}\text { Staging: } \\
\text { post-op brain MRI } \\
\text { pre or post-op spine MRI } \\
\text { CSF cytology } \\
\text { No Grading (currently) }\end{array}$ & $\begin{array}{l}\text { Radical resection improves } \\
\text { prognosis }\end{array}$ & $\begin{array}{l}\text { CSRT }+ \\
\text { primary site boost }\end{array}$ & $\begin{array}{l}\text { Some form of adjuvant } \\
\text { CHT indicated }\end{array}$ & \\
\hline Medulloblastoma & & & Radical resection improves & & & \\
\hline Average-Risk & & $\begin{array}{l}\text { No Metastases }(\mathrm{M} 0) \\
<1.5 \mathrm{~cm}^{2} \text { residual }\end{array}$ & prognosis & $\begin{array}{l}\text { Reduced-dose } \\
\text { CSRT ( } 24 \text { Gy) }\end{array}$ & $\begin{array}{l}\text { Platinum-based } \\
\text { adjuvant CHT }\end{array}$ & $\begin{array}{l}80 \% \\
5-y r \text { PFS }\end{array}$ \\
\hline High-Risk & & $\begin{array}{l}+ \text { Metastases }(\geq \mathrm{M} 1+) \\
\text { or } \\
>1.5 \mathrm{~cm}^{2} \text { residual }\end{array}$ & & $\begin{array}{l}\text { Standard-dose } \\
\text { CSRT (36 Gy) }\end{array}$ & $\begin{array}{l}\text { Platinum-based } \\
\text { adjuvant CHT } \\
+/- \text { radiosensitizer } \\
\text { CHT during RT }\end{array}$ & $\begin{array}{l}60-80 \% \\
5-y r \text { PFS }\end{array}$ \\
\hline Infant ( $\leq 3 \mathrm{yrs})$ & & $\begin{array}{l}+/-\mathrm{M} 0 \text { or } \mathrm{M} 1+ \\
+/- \text { residual }>1.5 \mathrm{~cm} 2\end{array}$ & & Defer RT & $\begin{array}{l}\text { Platinum-based } \\
\text { multiagent } \mathrm{CHT}\end{array}$ & $\begin{array}{l}30-60 \% \\
5-y r \text { PFS }\end{array}$ \\
\hline Supratentorial PNET & & $\begin{array}{l}+/-\mathrm{M} 0 \text { or } \mathrm{M} 1+ \\
+/- \text { residual }>1.5 \mathrm{~cm} 2\end{array}$ & $\begin{array}{l}\text { Radical resection improves } \\
\text { prognosis }\end{array}$ & $\begin{array}{l}\text { Standard-dose } \\
\text { CSRT }(36 \text { Gy })+ \\
\text { primary site boost }\end{array}$ & $\begin{array}{l}\text { Platinum-based } \\
\text { adjuvant CHT } \\
+/- \text { radiosensitizer } \\
\text { CHT during RT }\end{array}$ & $\begin{array}{l}50-60 \% \\
5-y r \text { PFS }\end{array}$ \\
\hline \multirow{2}{*}{$\begin{array}{l}\text { Glioma/Astrocytoma } \\
\text { Low-Grade Glioma } \\
\text { Cerebellum }\end{array}$} & & \multicolumn{2}{|c|}{ No Staging (unless symptoms) } & & & \\
\hline & $\begin{array}{l}\text { Brain MRI } \\
\text { Histology }\end{array}$ & $\begin{array}{l}\text { Grade: } \\
\text { Pilocytic Astrocytoma } \\
\text { (most) }\end{array}$ & $\begin{array}{l}\text { Radical resection } \\
\text { frequently curative }\end{array}$ & Rarely required & Rarely required & $\begin{array}{l}>90 \% \\
5-\mathrm{yr} \text { PFS }\end{array}$ \\
\hline $\begin{array}{l}\text { Supratentorial } \\
\text { midline OPHG }\end{array}$ & $\begin{array}{l}\text { Brain MRI } \\
\text { No Histology } \\
\text { (not routine) }\end{array}$ & $\begin{array}{l}\text { Grade: } \\
\text { Presumed Pilocytic or } \\
\text { Low- Grade Astrocytoma }\end{array}$ & Rarely resectable & $\begin{array}{l}\text { Conformal RT for } \\
\text { prog dz (older } \\
\text { child) }\end{array}$ & $\begin{array}{l}\text { CHT to defer RT in } \\
\text { younger children } \\
\text { (carboplatin/VCR or } \\
\text { PCV-TG) }\end{array}$ & $\begin{array}{l}40-80 \% \\
4-y r \text { PFS }\end{array}$ \\
\hline Cerebral & $\begin{array}{l}\text { Brain MRI } \\
\text { Histology }\end{array}$ & $\begin{array}{l}\text { Grade: } \\
\text { Pilocytic Astocytoma, } \\
\text { Low-grade Astrocytoma, } \\
\text { Mixed Glioma, or Other }\end{array}$ & $\begin{array}{l}\text { Radical resection may be } \\
\text { curative }\end{array}$ & $\begin{array}{l}+/- \text { Conformal RT } \\
\text { for residual/prog. dz } \\
\text { (older children) }\end{array}$ & Rarely indicated & $\begin{array}{l}80 \% \\
5-y r \text { PFS }\end{array}$ \\
\hline High-Grade Glioma & & & & & & \\
\hline Brainstem/Pontine & $\begin{array}{l}\text { Brain MRI } \\
\text { No Histology } \\
\text { (rarely) }\end{array}$ & $\begin{array}{l}\text { Grade: } \\
\text { Presumed Anaplastic } \\
\text { Astrocytoma or GBM }\end{array}$ & Not resectable & $\begin{array}{l}\text { Conformal RT } \\
\text { (rarely curative) }\end{array}$ & $\begin{array}{l}\text { Radiosensitizer CHT } \\
\text { during RT } \\
\text { (investigational) }\end{array}$ & $\begin{array}{l}\leq 5 \% \\
5-\mathrm{yr} \text { PFS }\end{array}$ \\
\hline Cerebral & $\begin{array}{l}\text { Brain MRI } \\
\text { Histology }\end{array}$ & $\begin{array}{l}\text { Grade: } \\
\text { Anaplastic Astrocytoma } \\
\text { or GBM }\end{array}$ & $\begin{array}{l}\text { Radical resection improves } \\
\text { prognosis }\end{array}$ & $\begin{array}{l}\text { Conformal RT } \\
\text { improves prognosis }\end{array}$ & $\begin{array}{l}\text { Adjuvant CHT may } \\
\text { improve prognosis }\end{array}$ & $\begin{array}{l}0-45 \% \\
5-y r \text { PFS }\end{array}$ \\
\hline
\end{tabular}

$\mathrm{CHT}=$ chemotherapy; GTR $=$ gross total resection; OPHG = optic pathway/hypothalamic glioma; $\mathrm{RT}=$ radiation therapy; $\mathrm{CSRT}=\mathrm{craniospinal}$ radiation therapy; $\mathrm{M} 0=$ no metastases; $\mathrm{PCV}-\mathrm{TG}=$ procarbazine/CCNU/vincristine-thioguanine; GBM = glioblastoma multiforme; M1 + = metastases(brain/spine/CSF cytology); PFS = progression-free survival. 
the anti-angiogenic agents, it seems likely that these drugs will not be as effective as single agents, and in future studies they will probably be combined with other small molecule inhibitors, chemotherapeutic or anti-angiogenic agents to assess their additive or synergistic potential.

\section{SUMMARY}

Important factors that have combined to improve the long term survival of children with brain tumors include advances in neuroimaging, histopathology, neurosurgery, and radiation therapy technologies, coupled with the application of conventional chemotherapy. MRI, MR spectroscopy, and diffusion-weighted MRI have contributed to the success. Neurosurgical treatment is facilitated by functional MRI, intra-operative image-guided stereotactic techniques and electrophysiological monitoring. The use of 3-D conformal RT, intensity-modulated RT, stereotactic radiosurgery and radiosensitizing agents have increased the efficacy and safety of RT. Chemotherapy regimens, administered either alone or combined with RT have improved the survival and quality-of-life of children with medulloblastoma/PNETs, high-grade and low grade gliomas. The improved outcome of children with brain tumors is, undoubtedly, also due to their treatment on collaborative national or multinational studies; this remains absolutely essential for progress to continue. Important new therapeutic approaches include refinement of drug delivery strategies, analysis of prognostic biologic markers to stratify patients for optimal therapy, and to exploit unique properties of tumor cells to target drug delivery. The thrust of such approaches is especially directed at reducing the toxicity of therapy and improving quality-of-life and increasing disease-free survival.

Acknowledgment: The author acknowledges support from National Childhood Cancer Foundation, Children's Oncology Chair Group - Chair's Grant; Subcontract 13101 under Grant U10CA98543-02; National Institutes of Health, Department of Health and Human Services.

\section{REFERENCES}

1. Rosser T, Packer RJ: Intracranial neoplasms in children with neurofibromatosis 1. J Child Neurol 17(8): 630-637; discussion 646-651, 2002.

2. Robertson PL, Allen JC, Abbott IR, Miller DC, Fidel J, Epstein FJ: Cervicomedullary tumors in children: a distinct subset of brainstem gliomas. Neurology 44(10): 1798-1803, 1994.

3. Albright AL, Packer RJ, Zimmerman R, Rorke LB, Boyett J, Hammond GD: Magnetic resonance scans should replace biopsies for the diagnosis of diffuse brain stem gliomas: a report from the Children's Cancer Group. Neurosurgery 33(6): 1026-1029; discussion 1029-1030, 1993.

4. Law M: MR spectroscopy of brain tumors. Top Magn Reson Imaging 15(5): 291-313, 2004.

5. Warren KE, Frank JA, Black JL, Hill RS, Duyn JH, Aikin AA, Lewis BK, Adamson PC, Balis FM: Proton magnetic resonance spectroscopic imaging in children with recurrent primary brain tumors. J Clin Oncol 18(5): 1020-1026, 2000.

6. Chenevert TL, Meyer CR, Moffat BA, Rehemtulla A, Mukherji SK, Gebarski SS, Quint DJ, Robertson PL, Lawrence TS, Junck L, Taylor JM, Johnson TD, Dong Q, Muraszko KM, Brunberg JA, Ross BD: Diffusion MRI: a new strategy for assessment of cancer therapeutic efficacy. Mol Imaging 1(4): 336-343, 2002.

7. Moffat BA, Chenevert TL, Lawrence TS, Meyer CR, Johnson TD, Dong Q, Tsien C, Mukherji S, Quint DJ, Gebarski SS, Robertson PL, Junck LR, Rehemtulla A, Ross BD: Functional diffusion map: a noninvasive MRI biomarker for early stratification of clinical brain tumor response. Proc Natl Acad Sci U S A 102(15): 5524-5529, 2005.

8. Gerdes J, Lemke H, Baisch H, Wacker HH, Schwab U, Stein H: Cell cycle analysis of a cell proliferation-associated human nuclear antigen defined by the monoclonal antibody Ki-67. J Immunol 133(4): 1710-1715, 1984.

9. Pollack IF, Hamilton RL, Burnham J, Holmes EJ, Finkelstein SD, Sposto R, Yates AJ, Boyett JM, Finlay JL: Impact of proliferation index on outcome in childhood malignant gliomas: results in a multi-institutional cohort. Neurosurgery 50(6): 1238-1244; discussion 1244-1235, 2002.

10. Fisher BJ, Naumova E, Leighton CC, Naumov GN, Kerklviet N, Fortin D, Macdonald DR, Cairncross JG, Bauman GS, Stitt L: Ki-67: a prognostic factor for low-grade glioma? Int J Radiat Oncol Biol Phys 52(4): 996-1001, 2002.

11. Grotzer MA, Geoerger B, Janss AJ, Zhao H, Rorke LB, Phillips PC: Prognostic significance of Ki-67 (MIB-1) proliferation index in childhood primitive neuroectodermal tumors of the central nervous system. Med Pediatr Oncol 36(2): 268-273, 2001.

12. Pollack IF, Finkelstein SD, Burnham J, Holmes EJ, Hamilton RL, Yates AJ, Finlay JL, Sposto R: Age and TP53 mutation frequency in childhood malignant gliomas: results in a multi-institutional cohort. Cancer Res 61(20): 7404-7407, 2001.

13. Tremont-Lukats IW, Gilbert MR: Advances in molecular therapies in patients with brain tumors. Cancer Control 10(2): 125137, 2003.

14. Pollack IF, Finkelstein SD, Woods J, Burnham J, Holmes EJ, Hamilton RL, Yates AJ, Boyett JM, Finlay JL, Sposto R: Expression of p53 and prognosis in children with malignant gliomas. $N$ Engl J Med 346(6): 420-427, 2002.

15. Sung T, Miller DC, Hayes RL, Alonso M, Yee H, Newcomb EW: Preferential inactivation of the p53 tumor suppressor pathway and lack of EGFR amplification distinguish de novo high grade pediatric astrocytomas from de novo adult astrocytomas. Brain Pathol 10(2): 249-259, 2000.

16. Segal RA, Goumnerova LC, Kwon YK, Stiles CD, Pomeroy SL: Expression of the neurotrophin receptor TrkC is linked to a favorable outcome in medulloblastoma. Proc Natl Acad Sci U S A 91(26): 12867-12871, 1994.

17. Scheurlen WG, Schwabe GC, Joos S, Mollenhauer J, Sorensen N, Kuhl J: Molecular analysis of childhood primitive neuroectodermal tumors defines markers associated with poor outcome. J Clin Oncol 16(7): 2478-2485, 1998.

18. Packer RJ, Cogen P, Vezina G, Rorke LB: Medulloblastoma: clinical and biologic aspects. Neuro-oncol 1(3): 232-250, 1999.

19. Pingoud-Meier C, Lang D, Janss AJ, Rorke LB, Phillips PC, Shalaby T, Grotzer MA: Loss of caspase- 8 protein expression correlates with unfavorable survival outcome in childhood medulloblastoma. Clin Cancer Res 9(17): 6401-6409, 2003.

20. Taipale J, Chen JK, Cooper MK, Wang B, Mann RK, Milenkovic L, Scott MP, Beachy PA: Effects of oncogenic mutations in Smoothened and Patched can be reversed by cyclopamine. Nature 406(6799): 1005-1009, 2000.

21. MacDonald TJ, Brown KM, LaFleur B, Peterson K, Lawlor C, Chen Y, Packer RJ, Cogen P, Stephan DA: Expression profiling of medulloblastoma: PDGFRA and the RAS/MAPK pathway as therapeutic targets for metastatic disease. Nat Genet 29(2): 143152, 2001.

22. Pomeroy SL, Tamayo P, Gaasenbeek M, Sturla LM, Angelo M, McLaughlin ME, Kim JY, Goumnerova LC, Black PM, Lau C, Allen JC, Zagzag D, Olson JM, Curran T, Wetmore C, Biegel JA, Poggio T, Mukherjee S, Rifkin R, Califano A, Stolovitzky G, 
Louis DN, Mesirov JP, Lander ES, Golub TR: Prediction of central nervous system embryonal tumour outcome based on gene expression. Nature 415(6870): 436-442, 2002.

23. Biegel JA, Zhou JY, Rorke LB, Stenstrom C, Wainwright LM, Fogelgren B: Germ-line and acquired mutations of INI1 in atypical teratoid and rhabdoid tumors. Cancer Res 59(1): 74-79, 1999.

24. Rezai AR, Mogilner AY, Cappell J, Hund M, Llinas RR, Kelly PJ: Integration of functional brain mapping in image-guided neurosurgery. Acta Neurochir Suppl 68: 85-89, 1997.

25. Duffner PK, Horowitz ME, Krischer JP, Burger PC, Cohen ME, Sanford RA, Friedman HS, Kun LE: The treatment of malignant brain tumors in infants and very young children: an update of the Pediatric Oncology Group experience. Neuro-oncol 1(2): 152161, 1999.

26. Kun L: Principles of Radiation Therapy. 2 ed. New York, Raven Press, 1994, pp 95-115.

27. Swift $P$ : Novel techniques in the delivery of radiation in pediatric oncology. Pediatr Clin North Am 49(5): 1107-1129, 2002.

28. Hodgson DC, Goumnerova LC, Loeffler JS, Dutton S, Black PM, Alexander E 3rd, Xu R, Kooy H, Silver B, Tarbell NJ: Radiosurgery in the management of pediatric brain tumors. Int J Radiat Oncol Biol Phys 50(4): 929-935, 2001.

29. Allen J, Siffert J, Donahue B, Nirenberg A, Jakacki R, Robertson P, DaRosso R, Thoron L, Rosovsky M, Pinto R: A phase I/II study of carboplatin combined with hyperfractionated radiotherapy for brainstem gliomas. Cancer 86(6): 1064-1069, 1999.

30. Ostryszja L: Gemcitabine and radiosensitization in two glioblasoma cell lines. Prec Amer Assoc Cancer Res (30): 382, 1998.

31. Yamanaka R, Homma J, Yajima N, Tsuchiya N, Sano M, Kobayashi T, Yoshida S, Abe T, Narita M, Takahashi M, Tanaka R: Clinical evaluation of dendritic cell vaccination for patients with recurrent glioma: results of a clinical phase I/II trial. Clin Cancer Res 11(11): 4160-4167, 2005.

32. De Vleeschouwer S, Van Calenbergh F, Demaerel P, Flamen P, Rutkowski S, Kaempgen E, Wolff JE, Plets C, Sciot R, Van Gool SW: Transient local response and persistent tumor control in a child with recurrent malignant glioma: treatment with combination therapy including dendritic cell therapy. Case report. $J \mathrm{Neu}$ rosurg 100(5 Suppl Pediatrics): 492-497, 2004.

33. Lumniczky K, Desaknai S, Mangel L, Szende B, Hamada H, Hidvegi EJ, Safrany G: Local tumor irradiation augments the antitumor effect of cytokine-producing autologous cancer cell vaccines in a murine glioma model. Cancer Gene Ther 9(1): 44-52, 2002.

34. Boskovitz A, Wikstrand CJ, Kuan CT, Zalutsky MR, Reardon DA, Bigner DD: Monoclonal antibodies for brain tumour treatment. Expert Opin Biol Ther 4(9): 1453-1471, 2004.

35. Martell LA, Agrawal A, Ross DA, Muraszko KM: Efficacy of transferrin receptor-targeted immunotoxins in brain tumor cell lines and pediatric brain tumors. Cancer Res 53(6): 1348-1353, 1993.

36. Weaver M, Laske DW: Transferrin receptor ligand-targeted toxin conjugate (Tf-CRM107) for therapy of malignant gliomas. J Neurooncol 65(1): 3-13, 2003.

37. Taipale J, Beachy PA: The Hedgehog and Wnt signalling pathways in cancer. Nature 411(6835): 349-354, 2001.

38. Kerbel R, Folkman J: Clinical translation of angiogenesis inhibitors. Nat Rev Cancer 2(10): 727-739, 2002.

39. Puduvalli VK, Sawaya R: Antiangiogenesis - therapeutic strategies and clinical implications for brain tumors. J Neurooncol 50(1-2): 189-200, 2000.

40. MacDonald TJ, Taga T, Shimada H, Tabrizi P, Zlokovic BV, Cheresh DA, Laug WE: Preferential susceptibility of brain tumors to the antiangiogenic effects of an alpha(v) integrin antagonist. Neurosurgery 48(1): 151-157, 2001.

41. Parsa A: Gene Therapy in Tumor of the Pediatric Central nervous System, in Keating R, (ed): Tumor of the Pediatric Netral Nervous System New York, Thieme, 2001, pp 184-195.

42. Izquierdo $\mathrm{M}$, Martin $\mathrm{V}$, de Felipe $\mathrm{P}$, Izquierdo JM, PerezHigueras A, Cortes ML, Paz JF, Isla A, Blazquez MG: Human malignant brain tumor response to herpes simplex thymidine kinase (HSVtk)/ganciclovir gene therapy. Gene Ther 3(6): 491-495, 1996.

43. Packer RJ, Raffel C, Villablanca JG, Tonn JC, Burdach SE, Burger K, LaFond D, McComb JG, Cogen PH, Vezina G, Kapcala LP: Treatment of progressive or recurrent pediatric malignant supratentorial brain tumors with herpes simplex virus thymidine kinase gene vector-producer cells followed by intravenous ganciclovir administration. J Neurosurg 92(2): 249-254, 2000.

44. Manome Y, Wen PY, Dong Y, Tanaka T, Mitchell BS, Kufe DW, Fine HA: Viral vector transduction of the human deoxycytidine kinase cDNA sensitizes glioma cells to the cytotoxic effects of cytosine arabinoside in vitro and in vivo. Nat Med 2(5): 567-573, 1996.

45. Cogen PH, McDonald JD: Tumor suppressor genes and medulloblastoma. J Neurooncol 29(1): 103-112, 1996.

46. Cheney IW, Johnson DE, Vaillancourt MT, Avanzini J, Morimoto A, Demers GW, Wills KN, Shabram PW, Bolen JB, Tavtigian SV, Bookstein R: Suppression of tumorigenicity of glioblastoma cells by adenovirus-mediated MMAC1/PTEN gene transfer. Cancer Res 58(11): 2331-2334, 1998.

47. Gondi CS, Lakka SS, Yanamandra N, Olivero WC, Dinh DH, Gujrati M, Tung CH, Weissleder R, Rao JS: Adenovirus-mediated expression of antisense urokinase plasminogen activator receptor and antisense cathepsin B inhibits tumor growth, invasion, and angiogenesis in gliomas. Cancer Res 64(12): 4069-4077, 2004.

48. Rorke LB: The cerebellar medulloblastoma and its relationship to primitive neuroectodermal tumors. J Neuropathol Exp Neurol 42(1): 1-15, 1983.

49. Duffner PK, Cohen ME, Myers MH, Heise HW: Survival of children with brain tumors: SEER Program, 1973-1980. Neurology 36(5): 597-601, 1986.

50. Dirks PB, Harris L, Hoffman HJ, Humphreys RP, Drake JM, Rutka JT: Supratentorial primitive neuroectodermal tumors in children. J Neurooncol 29(1): 75-84, 1996.

51. Albright AL, Wisoff JH, Zeltzer PM, Boyett JM, Rorke LB, Stanley P: Effects of medulloblastoma resections on outcome in children: a report from the Children's Cancer Group. Neurosurgery 38(2): 265-271, 1996.

52. Albright AL, Wisoff JH, Zeltzer P, Boyett J, Rorke LB, Stanley P, Geyer JR, Milstein JM: Prognostic factors in children with supratentorial (nonpineal) primitive neuroectodermal tumors. A neurosurgical perspective from the Children's Cancer Group. Pediatr Neurosurg 22(1): 1-7, 1995.

53. Evans AE, Jenkin RD, Sposto R, Ortega JA, Wilson CB, Wara W, Ertel IJ, Kramer S, Chang CH, Leikin SL, et al.: The treatment of medulloblastoma. Results of a prospective randomized trial of radiation therapy with and without $\mathrm{CCNU}$, vincristine, and prednisone. J Neurosurg 72(4): 572-582, 1990.

54. Krischer JP, Ragab AH, Kun L, Kim TH, Laurent JP, Boyett JM, Cornell CJ, Link M, Luthy AR, Camitta B: Nitrogen mustard, vincristine, procarbazine, and prednisone as adjuvant chemotherapy in the treatment of medulloblastoma. A Pediatric Oncology Group study. J Neurosurg 74(6): 905-909, 1991.

55. Tait DM, Thornton-Jones H, Bloom HJ, Lemerle J, Morris-Jones P: Adjuvant chemotherapy for medulloblastoma: the first multicentre control trial of the International Society of Paediatric Oncology (SIOP I). Eur J Cancer 26(4): 464-469, 1990.

56. Packer RJ, Sutton LN, Elterman R, Lange B, Goldwein J, Nicholson HS, Mulne L, Boyett J, D'Angio G, Wechsler-Jentzsch $\mathrm{K}$, et al.: Outcome for children with medulloblastoma treated with radiation and cisplatin, $\mathrm{CCNU}$, and vincristine chemotherapy. J Neurosurg 81(5): 690-698, 1994.

57. Strother D, Ashley D, Kellie SJ, Patel A, Jones-Wallace D, Thompson S, Heideman R, Benaim E, Krance R, Bowman L, Gajjar A: Feasibility of four consecutive high-dose chemotherapy cycles with stem-cell rescue for patients with newly diagnosed medulloblastoma or supratentorial primitive neuroectodermal tumor after craniospinal radiotherapy: results of a collaborative study. J Clin Oncol 19(10): 2696-2704, 2001.

58. Reddy AT, Janss AJ, Phillips PC, Weiss HL, Packer RJ: Outcome for children with supratentorial primitive neuroectodermal tumors 
treated with surgery, radiation, and chemotherapy. Cancer 88(9): 2189-2193, 2000.

59. Thomas PR, Deutsch M, Kepner JL, Boyett JM, Krischer J, Aronin P, Albright L, Allen JC, Packer RJ, Linggood R, Mulhern R, Stehbens JA, Langston J, Stanley P, Duffner P, Rorke L, Cherlow J, Friedman HS, Finlay JL, Vietti TJ, Kun LE: Lowstage medulloblastoma: final analysis of trial comparing standarddose with reduced-dose neuraxis irradiation. J Clin Oncol 18(16): 3004-3011, 2000.

60. Jakacki RI, Feldman H, Jamison C, Boaz JC, Luerssen TG, Timmerman R: A pilot study of preirradiation chemotherapy and 1800 cGy craniospinal irradiation in young children with medulloblastoma. Int J Radiat Oncol Biol Phys 60(2): 531-536, 2004.

61. Bailey CC, Gnekow A, Wellek S, Jones M, Round C, Brown J, Phillips A, Neidhardt MK: Prospective randomised trial of chemotherapy given before radiotherapy in childhood medulloblastoma. International Society of Paediatric Oncology (SIOP) and the (German) Society of Paediatric Oncology (GPO): SIOP II. Med Pediatr Oncol 25(3): 166-178, 1995.

62. Wara WM, Le QT, Sneed PK, Larson DA, Prados MD, Levin VA, Edwards MS, Weil MD: Pattern of recurrence of medulloblastoma after low-dose craniospinal radiotherapy. Int $J$ Radiat Oncol Biol Phys 30(3): 551-556, 1994.

63. Packer RJ: 2340cGy of Craniospinal Radiotherapy (CSRT) plus Chemotherapy for Children with "Average-Risk" Medulloblastoma (MB): A Prospective Randomized Children's Oncology Group Study (A9961).Society for Neuroncology Meeting, 2004.

64. Geyer JR, Zeltzer PM, Boyett JM, Rorke LB, Stanley P, Albright AL, Wisoff JH, Milstein JM, Allen JC, Finlay JL, et al.: Survival of infants with primitive neuroectodermal tumors or malignant ependymomas of the CNS treated with eight drugs in 1 day: a report from the Childrens Cancer Group. J Clin Oncol 12(8): 1607-1615, 1994.

65. Ater JL, van Eys J, Woo SY, Moore B 3rd, Copeland DR, Bruner J: MOPP chemotherapy without irradiation as primary postsurgical therapy for brain tumors in infants and young children. $\mathrm{J} \mathrm{Neu}$ rooncol 32(3): 243-252, 1997.

66. White L, Johnston H, Jones R, Mameghan H, Nayanar V, McWhirter W, Kellie S, Waters K, Toogood I: Postoperative chemotherapy without radiation in young children with malignant non-astrocytic brain tumours. A report from the Australia and New Zealand Childhood Cancer Study Group (ANZCCSG). Cancer Chemother Pharmacol 32(5): 403-406, 1993.

67. Kuhl JB, J; Bode, U; Deinlein, F.; Gnekow, A.; Graf, N.; et al: Delayed radiation therapy (RT) after postoperative chemotherapy $(\mathrm{PCH})$ in children less than 3 years of age with medulloblastoma. Results of the HIT-SKK' 87 and preliminary results of the pilot trial HIT-SKK'92. Med Pediatr Oncol 25: 250, 1995.

68. Grill J, Sainte-Rose C, Jouvet A, Gentet JC, Lejars O, Frappaz D, Doz F, Rialland X, Pichon F, Bertozzi AI, Chastagner P, Couanet D, Habrand JL, Raquin MA, Le Deley MC, Kalifa C: Treatment of medulloblastoma with postoperative chemotherapy alone: an SFOP prospective trial in young children. Lancet Oncol 6(8): 573-580, 2005.

69. Dupuis-Girod S, Hartmann O, Benhamou E, Doz F, Mechinaud F, Bouffet E, Coze C, Kalifa C: Will high dose chemotherapy followed by autologous bone marrow transplantation supplant cranio-spinal irradiation in young children treated for medulloblastoma? J Neurooncol 27(1): 87-98, 1996.

70. Guruangan S, Dunkel IJ, Goldman S, Garvin JH, Rosenblum M, Boyett JM, Gardner S, Merchant TE, Gollamudi S, Finlay JL: Myeloablative chemotherapy with autologous bone marrow rescue in young children with recurrent malignant brain tumors. J Clin Oncol 16(7): 2486-2493, 1998.

71. Merchant TE, Happersett L, Finlay JL, Leibel SA: Preliminary results of conformal radiation therapy for medulloblastoma. Neuro-oncol 1(3): 177-187, 1999.

72. Wolden SL, Dunkel IJ, Souweidane MM, Happersett L, Khakoo Y, Schupak K, Lyden D, Leibel SA: Patterns of failure using a conformal radiation therapy tumor bed boost for medulloblastoma. J Clin Oncol 21(16): 3079-3083, 2003.

73. Hallahan AR, Pritchard JI, Chandraratna RA, Ellenbogen RG, Geyer JR, Overland RP, Strand AD, Tapscott SJ, Olson JM:
BMP-2 mediates retinoid-induced apoptosis in medulloblastoma cells through a paracrine effect. Nat Med 9(8): 1033-1038, 2003.

74. Hirsch JF, Sainte Rose C, Pierre-Kahn A, Pfister A, Hoppe-Hirsch E: Benign astrocytic and oligodendrocytic tumors of the cerebral hemispheres in children. J Neurosurg 70(4): 568-572, 1989.

75. Albright AL: Pediatric brain tumors. CA Cancer J Clin 43(5): 272-288, 1993.

76. Kortmann RD, Timmermann B, Taylor RE, Scarzello G, Plasswilm L, Paulsen F, Jeremic B, Gnekow AK, Dieckmann K, Kay S, Bamberg M: Current and future strategies in radiotherapy of childhood low-grade glioma of the brain. Part I: Treatment modalities of radiation therapy. Strahlenther Onkol 179(8): 509-520, 2003.

77. Rush JA, Younge BR, Campbell RJ, MacCarty CS: Optic glioma. Long-term follow-up of 85 histopathologically verified cases. Ophthalmology 89(11): 1213-1219, 1982.

78. Alvord EC, Jr., Lofton S: Gliomas of the optic nerve or chiasm. Outcome by patients' age, tumor site, and treatment. J Neurosurg 68(1): 85-98, 1988.

79. Deliganis AV, Geyer JR, Berger MS: Prognostic significance of type 1 neurofibromatosis (von Recklinghausen Disease) in childhood optic glioma. Neurosurgery 38(6): 1114-1118; discussion 1118-1119, 1996.

80. Pierce SM, Barnes PD, Loeffler JS, McGinn C, Tarbell NJ: Definitive radiation therapy in the management of symptomatic patients with optic glioma. Survival and long-term effects. Cancer 65(1): 45-52, 1990.

81. Radcliffe J, Packer RJ, Atkins TE, Bunin GR, Schut L, Goldwein JW, Sutton LN: Three- and four-year cognitive outcome in children with noncortical brain tumors treated with whole-brain radiotherapy. Ann Neurol 32(4): 551-554, 1992.

82. Petronio J, Edwards MS, Prados M, Freyberger S, Rabbitt J, Silver P, Levin VA: Management of chiasmal and hypothalamic gliomas of infancy and childhood with chemotherapy. J Neurosurg 74(5): 701-708, 1991.

83. Packer RJ, Lange B, Ater J, Nicholson HS, Allen J, Walker R, Prados M, Jakacki R, Reaman G, Needles MN, et al.: Carboplatin and vincristine for recurrent and newly diagnosed low-grade gliomas of childhood. J Clin Oncol 11(5): 850-856, 1993.

84. Mahoney DH, Jr., Cohen ME, Friedman HS, Kepner JL, Gemer L, Langston JW, James HE, Duffner PK, Kun LE: Carboplatin is effective therapy for young children with progressive optic pathway tumors: a Pediatric Oncology Group phase II study. Neurooncol 2(4): 213-220, 2000.

85. Packer RJ, Ater J, Allen J, Phillips P, Geyer R, Nicholson HS, Jakacki R, Kurczynski E, Needle M, Finlay J, Reaman G, Boyett JM: Carboplatin and vincristine chemotherapy for children with newly diagnosed progressive low-grade gliomas. J Neurosurg 86(5): 747-754, 1997.

86. Merchant TE, Zhu Y, Thompson SJ, Sontag MR, Heideman RL, Kun LE: Preliminary results from a Phase II trail of conformal radiation therapy for pediatric patients with localised low-grade astrocytoma and ependymoma. Int J Radiat Oncol Biol Phys 52(2): 325-332, 2002.

87. Saran FH, Baumert BG, Khoo VS, Adams EJ, Garre ML, Warrington AP, Brada M: Stereotactically guided conformal radiotherapy for progressive low-grade gliomas of childhood. Int $J$ Radiat Oncol Biol Phys 53(1): 43-51, 2002.

88. Packer RJ, Boyett JM, Zimmerman RA, Rorke LB, Kaplan AM, Albright AL, Selch MT, Finlay JL, Hammond GD, Wara WM: Hyperfractionated radiation therapy (72 Gy) for children with brain stem gliomas. A Childrens Cancer Group Phase I/II Trial. Cancer 72(4): 1414-1421, 1993.

89. Broniscer A, Iacono L, Chintagumpala M, Fouladi M, Wallace D, Bowers DC, Stewart C, Krasin MJ, Gajjar A: Role of temozolomide after radiotherapy for newly diagnosed diffuse brainstem glioma in children: results of a multiinstitutional study (SJHG98). Cancer 103(1): 133-139, 2005.

90. Sanghavi SN, Needle MN, Krailo MD, Geyer JR, Ater J, Mehta MP: A phase I study of topotecan as a radiosensitizer for brainstem glioma of childhood: first report of the Children's Cancer Group-0952. Neuro-oncol 5(1): 8-13, 2003.

91. Wisoff JH, Boyett JM, Berger MS, Brant C, Li H, Yates AJ, McGuire-Cullen P, Turski PA, Sutton LN, Allen JC, Packer RJ, 
Finlay JL: Current neurosurgical management and the impact of the extent of resection in the treatment of malignant gliomas of childhood: a report of the Children's Cancer Group trial no. CCG-945. J Neurosurg 89(1): 52-59, 1998.

92. Sposto R, Ertel IJ, Jenkin RD, Boesel CP, Venes JL, Ortega JA, Evans AE, Wara W, Hammond D: The effectiveness of chemotherapy for treatment of high grade astrocytoma in children: results of a randomized trial. A report from the Childrens Cancer Study Group. J Neurooncol 7(2): 165-177, 1989.

93. Finlay JL, Boyett JM, Yates AJ, Wisoff JH, Milstein JM, Geyer JR, Bertolone SJ, McGuire P, Cherlow JM, Tefft M, et al.: Randomized phase III trial in childhood high-grade astrocytoma comparing vincristine, lomustine, and prednisone with the eightdrugs-in-1-day regimen. Childrens Cancer Group. J Clin Oncol 13(1): 112-123, 1995.

94. Wolff JE, Gnekow AK, Kortmann RD, Pietsch T, Urban C, Graf N, Kuhl J: Preradiation chemotherapy for pediatric patients with high-grade glioma. Cancer 94(1): 264-271, 2002.

95. Lashford LS, Thiesse P, Jouvet A, Jaspan T, Couanet D, Griffiths PD, Doz F, Ironside J, Robson K, Hobson R, Dugan M, Pearson AD, Vassal G, Frappaz D: Temozolomide in malignant gliomas of childhood: a United Kingdom Children's Cancer Study Group and French Society for Pediatric Oncology Intergroup Study. J Clin Oncol 20(24): 4684-4691, 2002.

96. Dolan ME, Pegg AE: O6-benzylguanine and its role in chemotherapy. Clin Cancer Res 3(6): 837-847, 1997.

97. Warren K, Gervais A, Aikin A, Egorin M, Balis FM: Pharmacokinetics of carboplatin administered with lobradimil to pediatric patients with brain tumors. Cancer Chemother Pharmacol 54(3): 206-212, 2004.

98. Weber F, Asher A, Bucholz R, Berger M, Prados M, Chang S, Bruce J, Hall W, Rainov NG, Westphal M, Warnick RE, Rand RW, Floeth F, Rommel F, Pan H, Hingorani VN, Puri RK: Safety, tolerability, and tumor response of IL4-Pseudomonas exotoxin (NBI-3001) in patients with recurrent malignant glioma. J Neurooncol 64(1-2): 125-137, 2003.

99. Di Sapio A, Morra I, Pradotto L, Guido M, Schiffer D, Mauro A: Molecular genetic changes in a series of neuroepithelial tumors of childhood. J Neurooncol 59(2): 117-122, 2002.

100. Raffel C, Frederick L, O'Fallon JR, Atherton-Skaff P, Perry A, Jenkins RB, James CD: Analysis of oncogene and tumor suppressor gene alterations in pediatric malignant astrocytomas reveals reduced survival for patients with PTEN mutations. Clin Cancer Res 5(12): 4085-4090, 1999. 